\author{
Active Inverted-F Antenna on Side of Small Conducting Plate \\ Mitsuo TAGUCHI* Yoshifumi YANAGISAKO** Kazumasa TANAKA \\ Dept. of Electrical \& Electronic Eng., Nagasaki University \\ ** Graduate School of Science and Technology, Nagasaki University \\ 1-14 Bunkyo-machi, Nagasaki-shi, 852-8521, Japan \\ E-mail: mtaguchi@net.nagasaki-u.ac.jp
}

\title{
Introduction
}

The digital terrestrial television broadcasting service will be started this year in Japan. For the antenna of the portable TV, the small sized antenna is desired. The inverted-F antenna is used as the antenna for the mobile communication terminal such as cellular phone due to its small size and ease of design and fabrication [1]. The characteristics of this antenna may be affected by the conducting materials in the vicinity of antenna. Therefore, in the design of such antenna, the existence of surrounding material must be considered.

In this paper, the active inverted-F antenna (AIFA) mounted on side of rectangular conducting plate of $182 \mathrm{~mm}$ by $18 \mathrm{~mm}$ is numerically and experimentally analyzed at the digital television frequency band. This antenna is fed by the coplanar waveguide (CPW) printed on the conducting plate. The conducting plate is located parallel to the B5-sized conducting plate. The electromagnetic simulator IE3D is used for the analysis of antenna [2].

\section{Analytical model}

Figure 1 shows the AIFA mounted on the side of rectangular conducting plate \#1 of $182 \mathrm{~mm}$ by $18 \mathrm{~mm}$. This small conducting plate is located parallel to the conducting plate \#2 of $182 \mathrm{~mm}$ by $252 \mathrm{~mm}$. The width of antenna element is $2 \mathrm{~mm}$. This antenna is fed by the CPW on the conducting plate \#1. The AIFA and CPW are printed on the PCB with the thickness of 1 $\mathrm{mm}$ and the relative permittivity of 4.2, and the loss tangent of 0.021 . The distance between the inverted-F antenna and the conducting plate \#2 is $2 \mathrm{~mm}$. Table 1 shows the antenna parameters. The silicon transistor 2SC3603 is integrated at the feed point. Figure 2 shows the amplifier circuit. In the numerical analysis of inverted-F antenna, the electromagnetic simulator IE3D based on the Method of Moment is used. The calculation frequencies are from $400 \mathrm{MHz}$ to $700 \mathrm{MHz}$. The cell size is $21.43 \mathrm{~mm}(\lambda / 20$ at $800 \mathrm{MHz})$ and the edge cell size is $1 \%$ of the cell size. The CPW is not considered in the numerical calculation. Although the infinite PCB is assumed in the numerical analysis, the PCB with size of $182 \mathrm{~mm}$ by h+24 mm is used in the test antenna.

\section{Actual gain}

The actual gain of active antenna is expressed as follows [3].

$$
G=\frac{\left|V_{O C}\right|^{2}}{\left|V_{O C}^{d}\right|^{2}} \times \frac{\left|S_{21}\right|^{2}\left|1-\Gamma_{S}\right|^{2}}{\left|S_{21}^{d}\right|^{2}\left|1-\Gamma_{S} S_{11}\right|^{2}},
$$

Where $V_{O C}$ is the open-circuit voltage at the feed point of inverted-F antenna, and $\Gamma_{S}$ is the reflection coefficient at the input port of amplifier circuit toward antenna. The superscript $\mathrm{d}$ denotes quantities related to the standard half-wave dipole antenna as the reference of gain. $\left|V_{\text {OC }}\right|^{2}$ is summarized in terms of the input resistance $R_{i n}$, the radiation pattern $G(\theta, \phi)$ and the incident electric field $\boldsymbol{E}_{0}$ as follows [4]. 

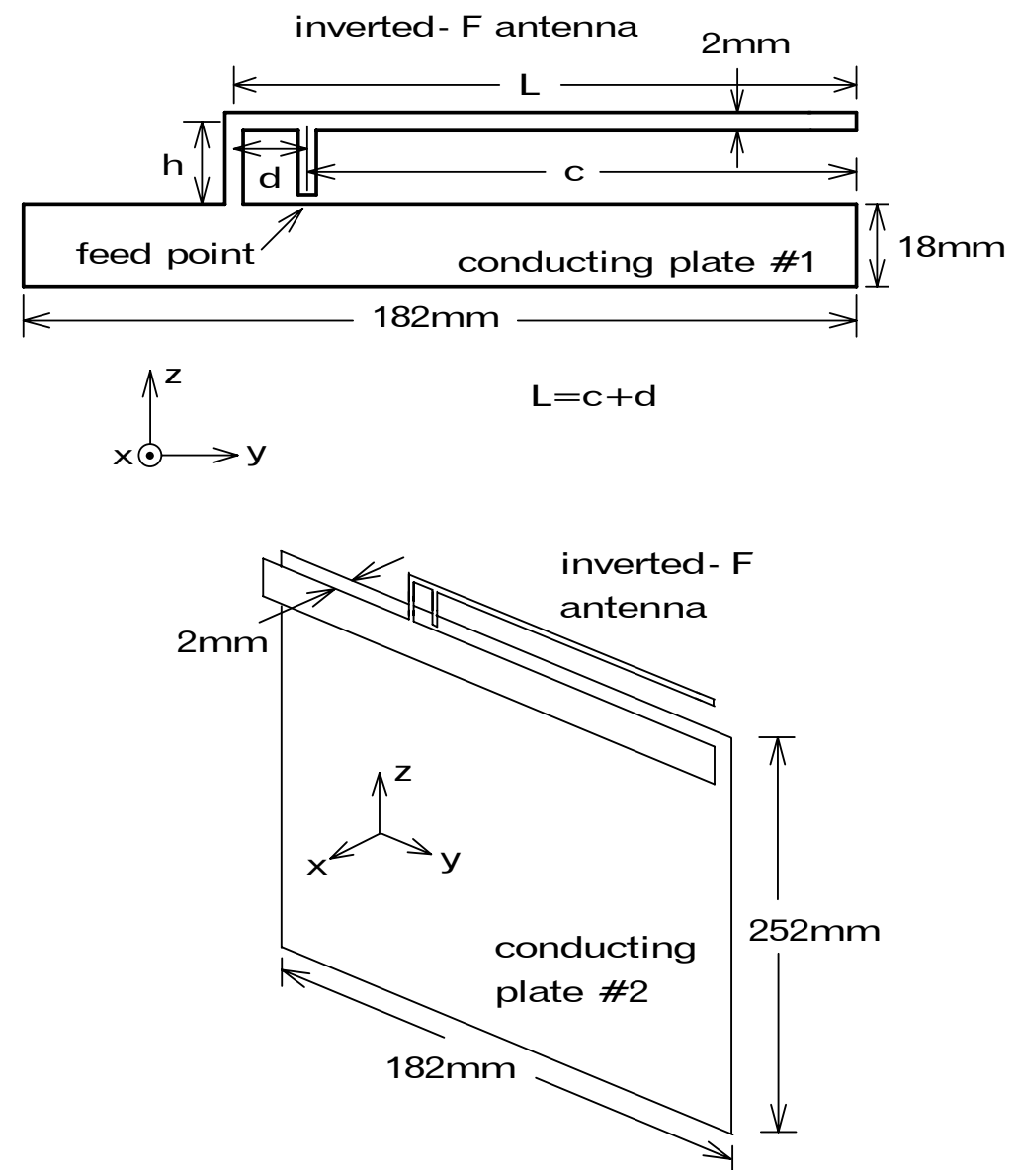

Figure 1 Inverted-F antenna mounted on side of small conducting plate.

$$
\left|V_{O C}\right|^{2}=\frac{4 \pi}{k^{2} \eta} R_{i n} G(\theta, \phi)\left|\boldsymbol{E}_{0}\right|^{2}
$$

\section{Results and discussion}

Figure 3 shows the calculated input impedance characteristics. Figure 4 shows the input impedance characteristics of antenna F-3 and the $S_{11}$ parameter of amplifier circuit. Figure 5 shows the return loss of antenna F-3. The discrepancy between the calculate and measured input impedances may be due to the existence of PCB. Since the distance between two conducting plates is $2 \mathrm{~mm}$, the mutual coupling between them may be strong. Therefore the difference of size of conducting plates between the calculation and measurement affects the input impedance characteristics. Figure 6 shows the actual gain of antenna F-3 in the $x$ direction. The actual gains are expressed in values relative to the half-wave dipole antenna. Due to the mismatching between the antenna and amplifier circuit, the measured actual gain becomes lower compared with the calculated results.

\section{Conclusion}

The active inverted-F antenna mounted on the side of rectangular conducting plate of $182 \mathrm{~mm}$ 
by $18 \mathrm{~mm}$ has been analyzed numerically and experimentally. The conducting plate is located parallel to the conducting plate of $182 \mathrm{~mm}$ by $252 \mathrm{~mm}$. This antenna is promising as the antenna of the digital terrestrial television receiver.

\section{References}

[1] K. Fujimoto, A. Henderson, K. Hirasawa and J. R. James, “Small Antennas”, Chapter 2, Research Studies Press Ltd., 1988.

[2] “IE3D User's manual Release 9”, Zeland Software, Inc., March 2002.

[3] M. Taguchi and T. Fujimoto: "Actual gain of CPW-fed active integrated antennas for television receiver”, IEICE Trans. on Communications, E81-B, 7, pp.1542-1547, July 1998.

[4] M. Taguchi, J. Araki and K. Tanaka: "Small-sized receiving active antenna on rectangular conductor”, IEICE Trans. on Communications, J85-B, 9, pp.1572-1574, Sept. 2002 (in Japanese).

Table 1 Antenna parameters.

\begin{tabular}{|c|c|c|c|c|}
\hline & $\mathrm{L}(\mathrm{mm})$ & $\mathrm{h}(\mathrm{mm})$ & $\mathrm{d}(\mathrm{mm})$ & $\mathrm{c}(\mathrm{mm})$ \\
\hline $\mathrm{F}-1$ & 120 & 11 & 5 & 115 \\
\hline F-2 & 120 & 11 & 3 & 117 \\
\hline F-3 & 115 & 16 & 5 & 110 \\
\hline F-4 & 115 & 16 & 3 & 112 \\
\hline
\end{tabular}

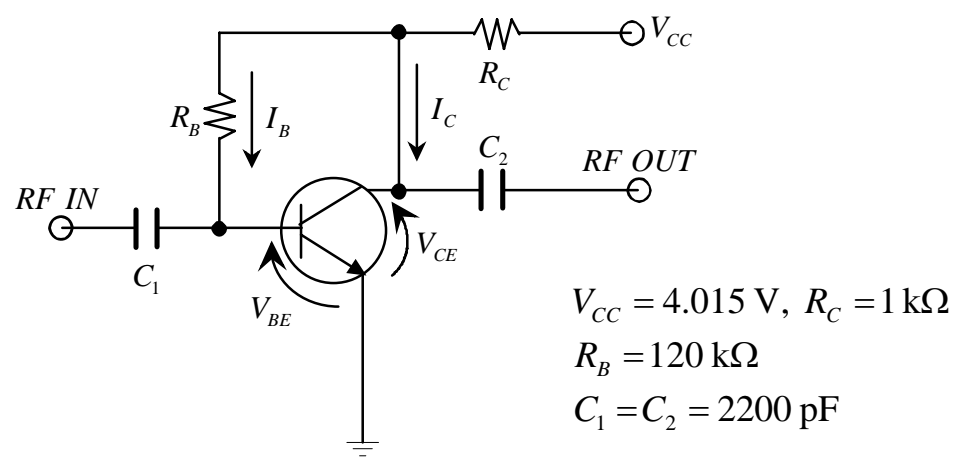

Figure 2 Amplifier circuit.

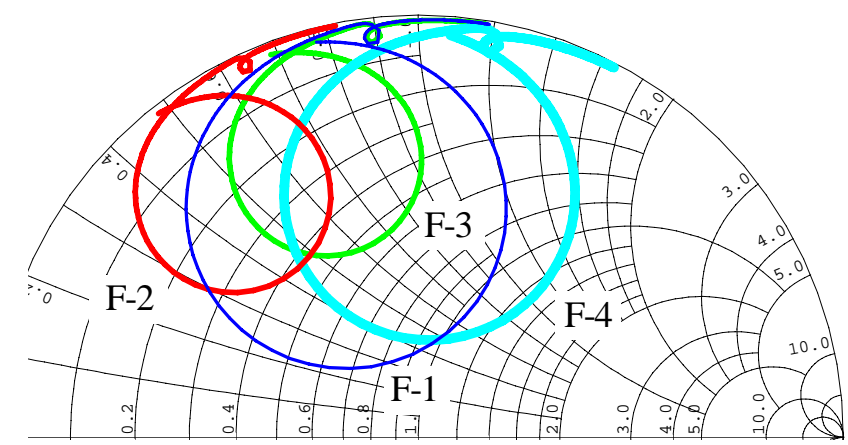

Figure 3 Calculated input impedance characteristics. 


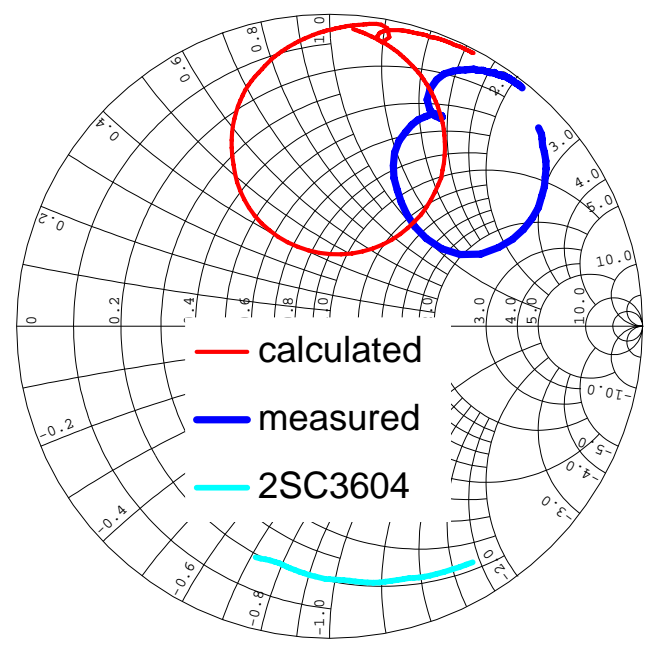

Figure 4 Input impedance of antenna F-3 and $S_{11}$ parameter of amplifier circuit.

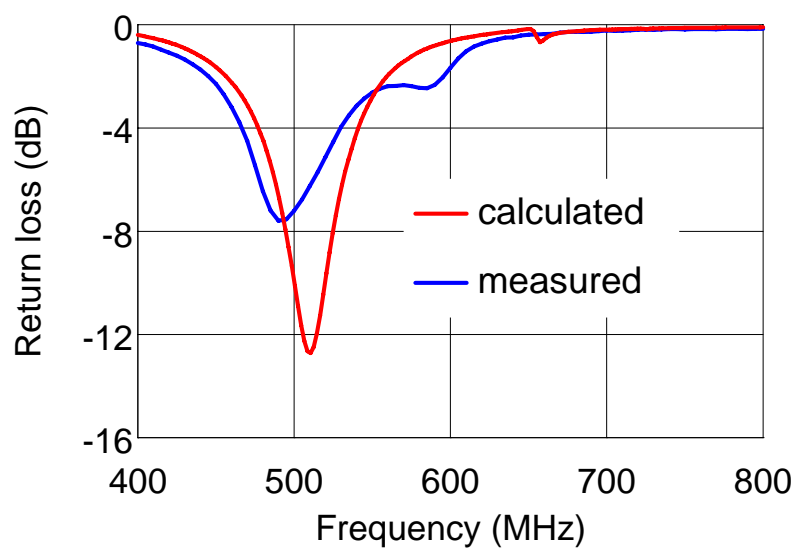

Figure 5 Return loss characteristics of antenna F-3.

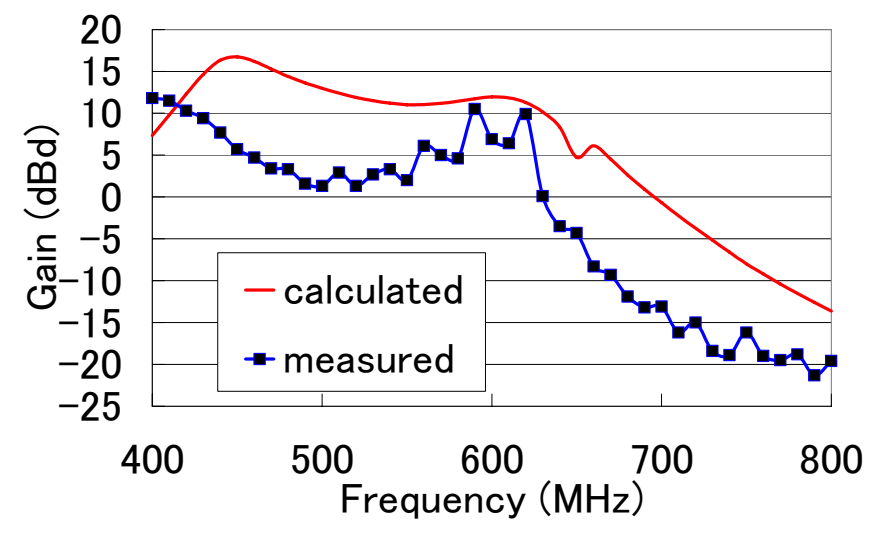

Figure 6 Actual gain of antenna F-3 in $\mathrm{x}$ direction. 